Behavior and Social Issues, 13, 152-154 (2004). C Sigrid S. Glenn \& Maria E. Malott. Readers of this article may copy it without the copyright owner's permission, if the author and publisher are acknowledged in the copy and the copy is used for educational, not-for-profit purposes.

\title{
ORGANIZATIONS AND INSTITUTIONS: REPLY TO ULMAN
}

\author{
Sigrid S. Glenn and Maria E. Malott
}

We share Ulman's (2004) interest in large scale social phenomena and the inequities that characterize modern societies concern us. But we are not convinced that an adequate scientific formulation exists for dealing with large scale social change. This should not stop any of us from doing what we can do to improve social conditions and using any conceptual framework available to try to understand how best to do that. We, like Ulman and others, are convinced that the concepts of behavior analysis can help us - both in developing an adequate formulation and in doing now what we can to improve social conditions. Meanwhile, we will try to address Ulman's suggestion that institutional economics provides a more useful approach than ours to analyzing cultural phenomena.

The term organization is so generic that it can be applied to almost any collection of interrelated events or objects. Bodies are organizations of cells, solar systems are organizations of planets, scientific conferences are organizations of paper presentations, etc. The necessary elements of an organization appear to be a set of particulars that relate to each other in such a way that they form a higher order particular that exists as an identifiable, nameable, entity. Organizations are usually classified in terms of their constituent elements. We were interested in cultural organizations, and defined an organization as "a group of people who perform tasks that achieve a product (including service delivery)" (p. 148). Ulman suggested that we defined "organization" too narrowly and that our organizations were a subclass of a more inclusive class of phenomena called institutions, which presumably includes organizations defined in other ways. He did not suggest any alternative definition of organization or explain what other "types of organizations" (his italics) make up the class institutions. We interpret Ulman as saying that institutions (not organizations - by any definition) are the phenomena of interest in cultural analysis. We will return to his discussion of institutions later, but we continue here with our definition of organization and its relevance to cultural analysis in general.

The constituent elements of cultural organizations are the recurring behaviors of people and the material and social environments supporting that behavior. For the most part, the supporting material environment is made up of the products of other cultural organizations. The elements of cultural organizations must be functionally related to one another (organized in a whole of some kind). What holds the elements together despite the gradual replacement of parts with other parts? How does an organization continue to exist when all of its constituent behavioral repertoires are gradually replaced? How does an organization's constituent elements become related into the organized whole that exists at a particular juncture in space and time? It appears to us that the successive iterations of related behaviors continue recurring because they function as a whole. And that brings us to the aggregate product part of our definition of organizations. The product is the organization's function, its reason for existing. 


\section{COMMENTARIES ON COMPLEXITY AND SELECTION}

We have taken this descriptive analysis a step further by suggesting that both the structure (component interlocking behavioral contingencies) and the function (products) of organizations exist, change, or cease as a result of external selecting environments. The application of the metacontingency principle to business organizations does not preclude application to other kinds of organizations any more than the application of operant principles to teaching dolphins precludes application to teaching college students. Although the particulars will differ greatly, depending on the type of organization, the principle remains the same.

Consider an organization formed to maintain neighborhood safety. The function (product) of the organization can be measured as rate of neighborhood crime. The reason such organizations are notoriously short lived may be that the product (crime rate) is not selected by an external environment. There is no independent receiving system. The organization's recurring interlocking contingencies are about as stable as operants maintained by "self-reinforcement". If the city made neighborhood improvements contingent on reducing crime rates, the interlocking behavioral contingencies of the neighborhood organization might have a better chance of recurring over extended time.

We are not suggesting that improvements are more valuable than safety - to us or to the hypothetical neighbors; in fact, we believe quite the opposite. But our beliefs (and the beliefs of the neighbors) are as beside the point in cultural analysis as they are in the analysis of behavior. The reason the suggested metacontingency arrangement is more likely to maintain the neighborhood organization's interlocking behavioral contingencies is because the product (lower crime) is selected by an external environment.

Ulman suggested that institutions, rather than organizations, should be the focus of cultural analysis. He finds, as one of us has found, that institutional economics offers valuable insights into modern cultures. But the concept of institution (as defined by Ulman, or in the literature he cited, or in our reading of the literature) covers too much territory to be a workhorse in a selectionist theory. The definitions provided are comparable in scope to "behavior" defined as the activities of living things, or to "living things" defined as DNA-based organic matter. No scientific analysis of behavior was possible as long as the activity of living things was the subject matter. A science of behavior awaited identification of the natural lines of fracture between behavior and environment that behavioral principles now describe. In institutional economics, many different kinds of things qualify as institutions and they do not function the same way as a class. For example, certain types of power relations (such as that between employer and worker) count as an institution. A specific organization (such as the University of North Texas) also counts. Types of things and individually named things play different roles in scientific analyses (Hull, 1977, 1980). To call them all "institutions" removes any possibility of identifying the classes that play a functional role in scientific generalizations.

Although the various institutional arrangements Ulman cites are no doubt ubiquitous in modern societies, they do not address the need for cultural units of analysis. As important as the insights of institutional economics may be, they do not address that 
need. Restating them in operant terminology may make them more accessible to behavior analysts, but it will not address the problem of accounting for cultural complexity.

We appreciate Ulman's deep interest in the need for social change and wish we could say that our analysis will lead directly to such change. In fact, we think that we have only offered a way to look at some of the cultural phenomena in which we are interested. We have found metacontingency analysis useful in our own work and believe others may find it useful as well.

\section{REFERENCE}

Hull, D. L. (1977). The ontological status of species as evolutionary units. In R. Butts \& J. Hintikka (Eds). Foundational problems in special sciences, 91-102. Dordrecht-Holland: D. Reidel Publishing Co. Reprinted in D. L. Hull (1989), The Metaphysics of evolution, pp.7088. Albany, NY: State University of New York Press.

Hull, D. L. (1980). Individuality and selection. Annual Review of Ecology and Systematics, 11, 311-332. Reprinted in D. L. Hull (1989), The Metaphysics of evolution, pp.89-109. Albany, NY: State University of New York Press.

Ulman, J. D. (2004). Institutions and macrocontinencies: Comments on Glenn and Malott's "Complexity and selection." Behavior and Social Issues, 13, 147-151.

http://dx.doi.org/10.5210/bsi.v13i2.28 